\title{
A review on today's burden affecting the quality of life for colour blind patients
}

\author{
Corina-Iuliana Suciu ${ }^{1,2}$, Vlad-Ioan Suciu ${ }^{3}$, Lacramioara Perju-Dumbrava ${ }^{3}$, \\ Simona Delia Nicoara ${ }^{1,4}$ \\ ${ }^{1}$ Department of Ophthalmology, Emergency County Hospital, Cluj-Napoca, Romania \\ ${ }^{2}$ University of Oradea, Romania \\ ${ }^{3}$ Department of Neuroscience, "Iuliu Hatieganu" University of Medicine and Pharmacy, \\ Cluj-Napoca, Romania \\ ${ }^{4}$ Department of Ophthalmology, "Iuliu Hatieganu" University of Medicine and Pharmacy, \\ Cluj-Napoca, Romania
}

\begin{abstract}
1.3 billion people worldwide suffer from a kind of visual impairment. Color blindness (dyschromatopsia) is a visual impairment affecting the quality of life for these patients and is estimated to be the highest in the male population of the European countries. This condition is determined by genetic mutations and secondary acquired etiologies. Many causes have no effective treatment, so new strategies in order to increase the quality of daily living for these people is mandatory. For any human, being independent is an important aspect in the society. Public awareness of this condition is also important. We believe that a simple tweak of the classic traffic lights is one solution to this problem.

Keywords: colour blindness, quality of life, traffic lights
\end{abstract}

\section{INTRODUCTION}

Colour blindness, or dyschromatopsia, is a condition which represents the failure of normal colour vision, rendering the patient disabled [1-3].

With this paper we aim to review the current literature regarding the subject of daily living for colour blind patients, and to focus the attention of the general population and healthcare professionals on the disability of colour blind individuals. We would also like to propose a new and simple traffic lighting tweak which could allow these individuals to function independently in traffic, thus increasing their quality of life.

\section{BACKGROUND}

The retina is a ten layered tissue within the eye which contains two main photoreceptor cells: cones and rods. The cones, which are grouped mainly within the macular region, receive bright light and are responsible for high resolution-color vision, while the rods, distributed in the rest of the retina, mediate the low light and monochromatic vision the scotopic vision. There are three types of cones, each responding to blue, green or red light $[1,3,4]$.

When the cones are dysfunctional or absent, the color perception is hindered. Dyschromatopsia is actually a spectrum of color vision dysfunction ranging from mild to severe forms. Beside the significant influence on the colour blind individuals' quality of life, another great concern arises in relation to traffic lights. These people are not allowed to drive vehicles of any kind and even their independency as citizens is restricted due to this condition $[1,4,5,18]$.

The causes of colour blindness are multiple. Many individuals are born with a congenital defect in the development of the retina with the full com- 
plement of all three types of cones. Other conditions leading to color blindness are the result of inflammatory, toxic, traumatic or metabolic factors acting on the retina or the optic nerve. Toxicity of various drugs and substances (digoxin, ethambutol, hydroxychloroquine, ethanol, methyl-alcohol) and diseases such as glaucoma, age related macular degeneration (AMD), Parkinson's disease and diabetes, are some of the most frequent causes of acquired color blindness [1,3-7,22].

OPN1LW, OPN1MW, OPN1SW genes are defective in different types of color vision impairments. These genes normally encode different opsin pigments in cones, which respond to different colors in the light spectrum: OPN1LW for yellow, OPN1MW for green and OPN1SW for blue (table 1) [8-13].

TABLE 1. Genetic aspects of congenital color blindness [8-21]

\begin{tabular}{|c|c|c|}
\hline Defective gene & Opsin coding & Inheritance pattern \\
\hline OPN1 LW & Yellow & X-linked recessive \\
\hline OPN1 MW & Green & X-linked recessive \\
\hline OPN1 SW & Blue & Autosomal dominant \\
\hline
\end{tabular}

Red-green color defect is the most encountered impairment; it affects predominantly men and has a $\mathrm{X}$-linked recessive inheritance. One in 12 males and one in 200 females have color vision deficits in North European communities. Other color vision impairments (such as blue-yellow deficits) are rare [8-21].

The World Health Organization (WHO) informed in 2018 by a fact sheet that globally there are more than 1.3 billion people worldwide suffering from one type of visual impairment (any etiology). The most frequent causes of visual impairment, according to $\mathrm{WHO}$, are: refractive errors, cataract, AMD, glaucoma, diabetic retinopathy, corneal opacity and trachoma. Three of these major conditions worldwide are also potential causes of color blindness [5-7]. Table 2 summarizes the causes of color blindness.

Color blindness can associate other neuro-ophthalmic symptoms or signs, such as nystagmus, photophobia or amblyopia $[1,4]$.

Chakrabarti et al. [14] emphasizes the need for awareness on the subject of quality of life in patients with colour vision disturbances [14].
TABLE 2. Causes of color blindness [1-22]

\begin{tabular}{|l|l|}
\hline HEREDITARY & $\begin{array}{l}\text { Developmental neuro-retinal defects } \\
\text { Progressive cone-rod dystrophy }\end{array}$ \\
\hline \multirow{5}{*}{ ACQUIRED } & $\begin{array}{l}\text { a. Toxic } \\
\text { - Drug toxicity (Digoxin, Ethambutol, } \\
\text { Hydroxychloroquine) } \\
\text { - Ethanol intoxication (chronic) } \\
\text { - Methyl alcohol intoxication (acute) } \\
\text { b. Inflammatory neuropathy (optic neuritis) } \\
\text { c. Miscellanea } \\
\text { - Age related macular disease (ARMD) } \\
\text { - Glaucoma } \\
\text { - Parkinson's disease } \\
\text { d. Metabolic disease } \\
\text { - Diabetes mellitus }\end{array}$ \\
\hline
\end{tabular}

Marechal et al. [15] insist that the late diagnosis of the hereditary forms of colour vision deficiencies has an impact on the quality of life and can interfere with the careers of these patients. Moreover, they explain that the hereditary forms affect $9 \%$ of male patients and $0.5 \%$ of female patients, most of them being related to the involvement of the X-chromosome. The red-green colour vision appears to be most affected [15].

Tsang et al [17] review an X-linked genetic disorder, with later onset (adulthood), called Progressive cone-rod dystrophy. As the name anticipates, the disorder is progressive and associates a severe visual acuity decrease in later stages [17].

Stoianov et al. [18] (2019) reviewed 20 studies related to the impact on the quality of life of patients with colour vision deficiencies and concluded that the support offered to these patients is today insufficient. They also emphasize on the need for implementing newer strategies to enable these people to live a better life [18].

Fanlo et al. [19] (2019) reviewed the current literature regarding the testing for colour vision deficiencies. Their work concluded that the most used clinical test was Ishihara (10.88\%) despite the fact that the Anomaloscope testing (1.28\%) being the gold standard in this field. This test is considered complex, difficult to apply to all patients and time consuming. Their recommendation is to use at least two different tests in order to ensure an accurate evaluation of colour deficiencies [19].

Simunovic [20] also notes that the colour deficiencies are classified into two separate categories - acquired and hereditary. The acquired form of colour vision deficiency is caused by lesions from ocular, neurologic or systemic diseases [20]. 


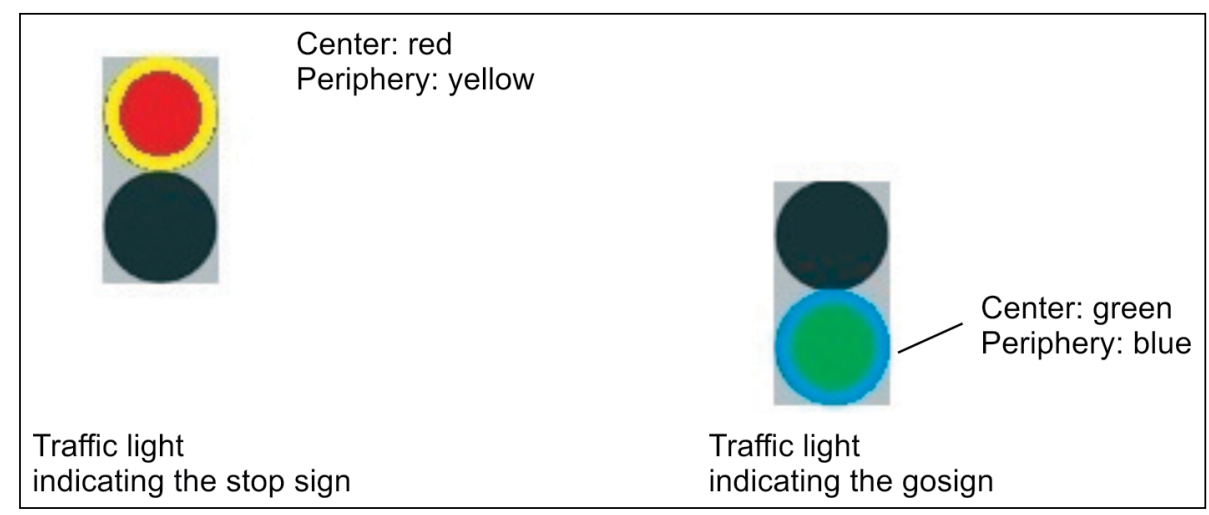

FIGURE 1. A suggestion for improved traffic lighting

Hofmann et al. [21] implied that the genetic mutations which cause colour vision disturbances affect the structure of $G$ protein-coupled receptors in the light sensitive receptors of the retina [21].

The management of colour blind patients is complex. Different causes mean different approaches to managing the disease. Some acquired causes can be effectively treated if the cause and effect are reversible. Congenital causes are however not treatable, rendering the patient colour blind all his/her life. Even some of the most frequent acquired causes such as drug toxicities, inflammatory neuropathies, glaucoma, Parkinson's disease or diabetes have unpredictable progression patterns, making the treatment more difficult $[4,6-8,22]$.

Hassall et al16 emphasize on the importance of AAV gene therapy for achromatopsia being more effective if applied early in the course of the disease (childhood). The isolated retinal cone disturbance is called achromatopsia and, according to Hassall, appears to be caused by multiple defective genes such as: CNGA3, CNGB3, GNAT2, PDE6H, PDE6C and ATF6. However, these genetic treatments are still in the phase of trials [16].

\section{SUGGESTION FOR IMPROVED TRAFFIC LIGHTING}

Since there is no widely available and effective cure for the hereditary forms of colour blindness and the outcome of the acquired ones is often unpredictable, efforts should be made in order to help these people in their routine activities, to render them independent and increase their quality of life.

First, the traffic light coding could be upgraded. The coding of the red light meaning "stop" and of the green light meaning "go" are well known and should be kept to avoid confusion. Therefore, we propose a simple tweak in traffic lights, enabling colour blind people to perceive them easier. The new traffic lighting system should have two colours for each sign (figure 1). The "stop" sign should have the center red and a peripheral yellow rim. The "go" sign should have the center green and a peripheral blue rim. Thus, most color blind individuals (red-green blindness, although suitable for most color vision impairments) will detect the yellow rim for "stop" and the blue rim for "go". Furthermore, the traffic lights should have only these two signals: "stop" and "go", eliminating the intermediate orange sign.

We believe that this simple idea might be helpful in assisting the colour blind individuals, alongside with other aids that have already been developed: drawings symbolizing the "stop" or the "go" sign, sound alerts, specially trained dogs.

\section{CONCLUSION}

Addressing this condition multidisciplinary with healthcare professionals, citizens and administrative organizations, colour blind people will ultimately have a better quality of life.

Conflict of interest: none declared Financial support: none declared 


\section{REFERENCES}

1. American Academy of Ophthalmology. Eye Health [Internet]. Turbert D. What is color blindness? [updated 06 September 2019]. Available from: https://www.aao.org/eye-health/diseases/what-is-color-blindness.

2. Bringmann A, Syrbe S, Görner K, Kacza J, Francke M, Wiedemann $P$, Reichenbach A. The primate fovea: Structure, function and development. Progress in Retinal and Eye Research. 2018; 66:49-84.

3. Ropper AH, Samuels MA, Klein JP. Adams and Victor's Principles of Neurology. Tenth Edition. China: McGraw-Hill Education; 2014.

4. National Eye Institute [Internet]. At a glance: Color blindness. [updated 3 July 2019]. Available from: https://nei.nih.gov/health/ color_blindness/facts_about.

5. World Health Organization [Internet]. Blindness and vision impairment [updated 8 October 2019]. Available from: https://www.who.int/ news-room/fact-sheets/detail/blindness-and-visual-impairment.

6. Bourne RRA, Flaxman SR, Braithwaite T, Cicinelli MV, Das A, Jonas $\mathrm{JB}$, et al. Vision Loss Expert Group. Magnitude, temporal trends, and projections of the global prevalence of blindness and distance and near vision impairment: a systematic review and meta-analysis. Lancet Glob Health. 2017;5(9):e888-97.

7. Fricke TR, Tahhan N, Resnikoff S, Papas E, Burnett A, Suit MH, Naduvilath T, Naidoo K. Global Prevalence of Presbyopia and Vision Impairment from Uncorrected Presbyopia: Systematic Review, Meta-analysis, and Modelling. Ophthalmology; 2018.

8. U.S. National Library of Medicine. Genetics Home Reference [Internet]. Color vision deficiency [updated 3 March 2020]. Available from: https://ghr.nlm.nih.gov/condition/color-visiondeficiency\#statistics.

9. Deeb SS. Molecular genetics of color-vision deficiencies. Vis Neurosci. 2004;21(3):191-6.

10. Deeb SS. The molecular basis of variation in human color vision. Clin Genet. 2005;67(5):369-77.
11. Gardner JC, Michaelides M, Holder GE, Kanuga N, Webb TR, Mollon JD, Moore AT, Hardcastle AJ. Blue cone monochromacy: causative mutations and associated phenotypes. Mol Vis. 2009;15:876-84.

12. Michaelides M, Hunt DM, Moore AT. The cone dysfunction syndromes. Br J Ophthalmol. 2004;88(2):291-7.

13. Neitz J, Neitz M. The genetics of normal and defective color vision. Vision Res. 2011;51(7):633-51.

14. Chakrabarti S. Psychosocial aspects of colour vision deficiency: Implications for a career in medicine. Natl Med J India. 2018; 31:86-96.

15. Marechal M, Delbarre M, Berguiga M, Benisty D, Froussart-Maille $F$. Hereditary color vision deficiency: Physiology, classification, diagnosis and application to aeronautics. J Fr Ophtalmol. 2019;42(2):177-188.

16. Hassall MM, Barnard AR, MacLaren RE. Gene Therapy for Color Blindness. Yale J Biol Med. 2017;90(4):543-551.

17. Tsang SH, Sharma T. Progressive Cone Dystrophy and Cone-Rod Dystrophy (XL, AD, and AR). Adv Exp Med Biol. 2018;1085:53-60.

18. Stoianov M, de Oliveira MS, dos Santos RS, et al. The impacts of abnormal color vision on people's life: An integrative review. Qual Life Res. 2019;28:855-862.

19. Fanlo Zarazaga A, Gutiérrez Vásquez J, Pueyo Royo V. Review of the main colour vision clinical assessment tests. Arch Soc Esp Oftalmol. 2019;94(1):25-32.

20. Simunovic MP. Acquired color vision deficiency. Surv Ophthalmol. 2016;61(2):132-55.

21. Hofmann L, Palczewski K. Advances in understanding the molecular basis of the first steps in color vision. Prog Retin Eye Res. 2015;49:46-66.

22. Guo L, Normando EM, Shah PA, De Groef L, Cordeiro MF. Oculo-visual abnormalities in Parkinson's disease: Possible value as biomarkers. Mov Disord. 2018;33(9):1390-406. 